\title{
Exploratory Study of Leadership Behavior Impact on Environmental Performance of Industrial Companies in Libya
}

\author{
Tarek Ahmed Alaati ${ }^{1}$, Muhammad Nizam ${ }^{2}$, Ary Setyawan ${ }^{3} \&$ Prabang Setyono $^{1}$ \\ ${ }^{1}$ Environmental Science Department, Sebelas Maret University of Surakarta, Indonesia \\ ${ }^{2}$ Electrical Engineering Department, Sebelas Maret University of Surakarta, Indonesia \\ ${ }^{3}$ Civil Engineering Department, Sebelas Maret University of Surakarta, Indonesia \\ Correspondence: Tarek Ahmed Alaati, Environmental Science Department, Sebelas Maret University of \\ Surakarta, Indonesia. E-mail: tarekalaati@yahoo.com
}

Received: September 28, 2015

Accepted: January 12, $2016 \quad$ Online Published: January 23, 2016

doi:10.5539/ijbm.v11n2p119

URL: http://dx.doi.org/10.5539/ijbm.v11n2p119

\begin{abstract}
This research purposed to investigate the impact of the leadership behaviour on environmental performance in Akakus Oil Operation Company in Libya. The case study conducted was specifically designed to investigate the connection between leadership behaviour style (supportive and directive leadership behaviour) and the implementation status based on international standard systems that is encompassed on total quality management (TQM) and environmental management system (EMS). TQM and EMS are crucial techniques to increase the environmental performance within industrial organizations. Survey was carried out to collect the primary data. Random sampling technique applied to get the data. 200 respondents who consisted of supervisor, managers and employees of Akakus Oil Operation Company, Libya were involved to participate on this study. The statistical result showed a strong relationship between the leadership behavior and environmental performance. Moreover, there are massive impacts of the leadership on environmental performance. In addition, the leadership behavior play important role in determining the overall implementation status of TQM key elements and EMS in the Libyan Organization. Further, this work contributes to the existed knowledge about empirical impact of the leadership behavior on environmental performance within the industrial and manufacturing companies in Libya. The variables were tested through different aspects to provide comprehensive views on the factors which affect the environmental performance in Akakus Oil Operation Company in Libya.
\end{abstract}

Keywords: leadership behavior, environment performance, Libya

\section{Introduction}

Environment becomes a daily major issue for industry and business in today's world. Industrial activities are polluting various natures such as water, air, and soil and plant vegetation (Singh \& Pandey, 2011). Nowadays, there has been thrived awareness of pollutions which caused global warming and ozone depletion. UNEP reported manufacture industry spend $35 \%$ of global electricity needs. It was $20 \%$ contributing on carbon emissions in the world, which are destructive for any life on the earth. Therefore, appropriate management and control strategies on the environmental issue required to retain global customers and to thrive a critical global economy (Chavan, 2005; Singh \& Shoura, 2006; Petros, Sebhatu, \& Enquist 2007). In this case, integrated management systems like Total Quality Management (TQM ISO 9001) and Environmental Management System (EMS ISO 14001) are developed to overcome environmental issues on each aspect of the company's operation. They also offer an efficient approach to handle environmental issue.

On the other hand, Leadership is an important managerial factor in any organization (Tatlah, Ali et al., 2011). Leadership of the managers, supervisors, and team leaders is main activator the implementation of TQM ISO 9001 and EMS ISO 14001. The most important factor in determining the overall success of development and implementation of TQM and EMSs is commitments of top management. Abdullah and Fuong stated that the top management commitment was a principle to improve awareness on environment issue (Haslinda \& Chan, 2010). They decide to establish environmental policies, the level of training and communication which required. These commitments must be based upon an understanding of the business value of an effective TQM, and EMS and the importance of integrating TQM and EMS into day-to-day operations. In addition this commitment should also be 
effectively communicated so that the TQM and EMS implementation team, as well as other employees, understands what is involved by top management commitments. This study mainly purposed to figure out the impact of leadership behaviour on the environmental performance. Moreover, to examine if there is any connection between leadership behavior style (supportive and directive leadership behaviour) and overall implementation status of international standard systems such as total quality management (TQM) and environmental management system (EMS) which they are very crucial techniques in increasing the environmental performance within the industrial organizations.

\section{Literature Review}

\subsection{Leadership Behavior}

Businesses, government agencies, non-profits, and educational organizations need leaders who are able to handle complexity, situation changes and as well as getting the job done (Leslie, 2009). Leadership is also determined as a process of an individual that influences a group of individuals to meet certain goals (Ewing Bruce et al., 2009). Burke and Barron explained leadership might be based on a function of personality, or it can be seen as a behavioral category, and related to motivation and to the process of communication, and the relationship between the leader and the management (Burke \& Barron, 2014). A good leader could help the companies to achieve their significant strategies. Leadership is as process of influencing individual or group activities to attempt objective achievement in an arranged situation. However, the leaders would meet the challenge to build 'change' which is to motivate people to do adaptive work.

There are several approaches in leadership discussion; Path-Goal theory is one leadership theory which is potential to suite future leadership concept. It proposes leaders to attempt the clearly path for subordinates to accomplish their goal (Saee, 2005). The Path-Goal leadership theory stated that leaders are considered effective because of their influences towards subordinates' motivation, adequate to perform effectively and satisfaction. This theory encourages the leader behaviour should motivate and persuade on the behaviour that improves subordinate goal achievement and defines the paths of these objectives clearly. (House \& Dessler, 1974).

Leadership is a major managerial factor in any organization (Tatlah, Ali et al., 2011). Leadership has to be hold by any leaders including managers, supervisors and even team leaders who responsible to run an organization, which means has main role in applying TQM ISO 9001 and EMS ISO 14001. Top management commitments determined as the base to success the development and implementation of TQM and EMSs. The top management commitment also is fundamental to improve environment. They have rights to establish the environmental policies, the required level of training and communication (Govindarajulu \& Daily, 2004; Haslinda \& Chan, 2010). These commitments must be based upon an understanding of the business value of an effective TQM and EMS and the importance of integrating TQM and EMS into day-to-day operations. In addition to this commitment should also be effectively communicated so that the TQM and EMS implementation team, as well as other employees, understands what is involved by top management commitments. Leadership behaviors were deeply appraised under multiple dimension views in Path-Goal Theory studies and it further corrected. There are four basic leadership behaviors were determined in Path-Goal Theory, which are supportive, directive, participative, and achievement oriented leadership behavior. This work proposed supportive and directive leadership.

\subsubsection{Supportive Leadership}

Rollinson stated that supportive leadership encompasses leadership behaviour as talking to people, encourage their efforts, hope establishment, problems solving, and participate them in decision-making process (Rollinson, 2008). Supportive leaders show cares to the subordinates through building an overt, friendly, and conducive group circumstance of workplace, and capable to manage co-worker equally (Lunenburg \& Ornstein, 2011). The involved emotions and personal expectations are considered in supportive leadership. Leaders are disposed to deviate from the path they follow for happiness and satisfaction of their followers (House, 1971).

\subsubsection{Directive Leadership}

According to House, directive leadership is a situation where leader directs completely and essentially on particular subject (House, 1971). Questions of what, how, where, when, and who on executing something are clearly assigned in directive leadership behaviour. Member performances of an organization are secretly appraised. The behaviour of directive leadership are ordering expectations subordinates or followers, planning, programing, controlling objective performance, and bringing out standards (Hanson, 2003; Rollinson, 2008). The leader commands directly about followers' roles so that they clearly understand the expected actions upon them, as well as problem solving and decision-making process are handled by leader. 


\subsection{Leadership Behavior and Environmental Performance}

Ulubeyli stated that Environment performance deals with the capability manufacture plants to reduce emissions, wastes tunnel, and solid waste including reducing the use of toxic and harmful materials (Ulubeyli, 2013). The most important management standard and systems that were being developed to deal apart with quality, environmental, health and safety issues respectively are DIS ISO 9001 and BS EN ISO 14001 (Wilkinson \& Dale, 2001). ISO 9001 encourage quality improvement and cost reducing which contributing to retain the customer's satisfaction successively (Han \& Chen, 2007), meanwhile ISO 14001 presents organized management system for any organization which intends to have environmental performance reformation by controlling their activities' impact, services and products toward its environments. It is also suited organization which intend to concern consistently towards environmental laws and policies. ISO 14001 and ISO 9001 have been developed to be fitted each other (Jørgensen, Remmen et al. 2006).

Several studies indicated a positive correlation between leadership behaviour and environmental performance (Beer, 2003; Govindarajulu \& Daily, 2004; Zutshi \& Sohal, 2004; Lakshman, 2006; Haslinda \& Chan, 2010; Rui, Emerson et al., 2010; Sinha \& Karaszewski, 2010). Therefore, leaders should understand that implementation status of international standard systems as well as total ISO 9001 of quality management and ISO 14001 of environmental management system. They become crucial techniques in increasing the environmental performance within the industrial organizations is crucial elements to be addressed to. TQM and EMS implementation is influenced by organizational environment created by the top management. Hoyle stated that the most important factor in determining the overall success of development and implementation of an EMS and TQM is the commitment of the top management (Hoyle, 2009). They added that the role of the top management is not confined to initial written statements, but should also include identifiable activities, addressing internal communications, employees' involvement in setting of goals and objectives and ensuring that adequate resources are available.

However, effective leadership that establish accurately and punctual communication support massively in increasing the level of TQM and EMS implementation. It significantly enhances superior environmental performance of a company. Based on the previous literature, the present study formulated the research hypotheses as follows;

1. There is a strong correlation among leadership behavior and environmental performance.

2. Leadership behavior has massive impacts on environmental performance.

\section{Methodology}

Figure 1 illustrates clearly framework of this study. It draws the variables of leadership behavior and environmental performance that were used in this study.

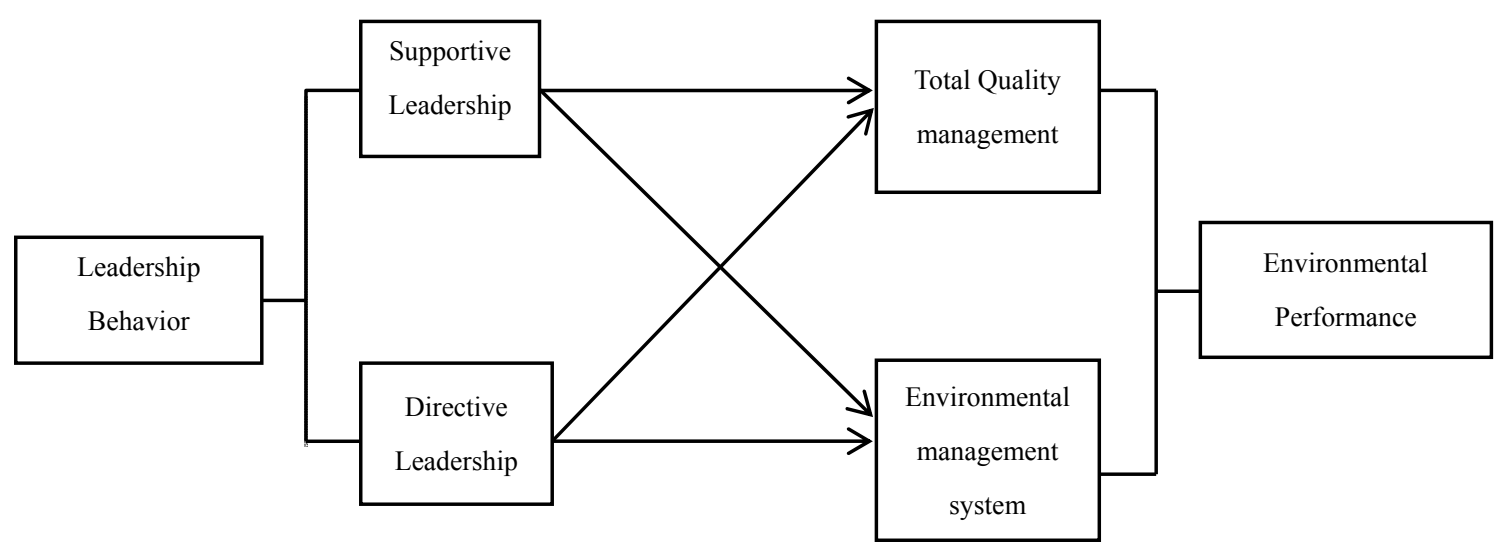

Figure 1. Concept of correlation between leadership and environmental performance

\subsection{Questionnaire Design}

Questionnaire survey was prepared to collect data on this study. The standard assessment aspects were based on the previous study. The questionnaire was divided into three sections; A: demographic profile; B: Supportive and Directive leadership Behaviour. Leadership Behaviour is answered as 1-Never, 2- Sometimes, 3- usually 4-Often, 
and 5-Always. C: Total Quality Management and Environmental Management System. The instrument here was utilized to obtain levels of top management commitment and employees' involvement to environmental policy, as well as to the extent environmental management objectives and targets were achieved. Multiple choice question was used and the respondents who answered on 'yes-no' form do not know scale to tick on the most appropriate answer based on their detailed knowledge.

\subsection{Data Collection}

The sample comprised company members who were working at Akakus Oil Operation Company in Libya. A total of 200 Questionnaires were submitted to the personal department and were subsequently distributed at random to the employees in different departments and at different levels within the company, and a total of 160 were returned, and 37 of the 160 were discarded because of missing data. Therefore, the number of usable questionnaires was $123(\mathrm{~N}=123)$. In other word, the response rate was $61.5 \%$ for Akakus Company.

\section{Findings}

\subsection{Descriptive Analyses}

The respondents for the present study were 123 employees working in different levels at Akakus Company in Libya. 116 respondents were male, while the consisted of female respondents. The majority of those employees sampled at Akakus Company were between the ages of $40-50$, there were $54.4 \%$ in this age group. $29.3 \%$ were between of 24-40; also 16.3 of the respondents' age group were over 50 years old. The majority of respondents at Akakus $61.8 \%$ were educated to graduate level, with $17.9 \%$ of them having a Masters, another $17.9 \%$ more had been educated to an intermediate diploma level and the remaining $3 \%$ only had secondary school. Although the vast majority of the respondents at Akakus had been educated in Libya, $91.1 \%$ in fact, there were $8.9 \%$ of the respondents who had travelled to Europe for their education. About $73.2 \%$ of respondents who completed the questionnaire were ordinary employee, while $18.7 \%$ of respondents were supervisors. There were $8.1 \%$ of respondents who completed the questionnaire were managers. The largest group of respondents at Akakus Company was $47.8 \%$ who had worked for 11 to 15 years, meanwhile $25.2 \%$ of respondents who had been with the company for 16 to 20 years. There were an equal amount of relatively new employees at the Oil Company who working with the company less than 5 years.

\subsection{Reliability Analysis}

Reliability analysis was carried out for each variable of leadership behaviour and environmental performance at Akakus Company. Cronbach's alpha was used as a measure of reliability to determine consistency of the scale. All variables showed an acceptable reliability range after factor loading was done. The supportive and directive leadership behaviour attained .79 and .88 respectively, while total quality management and environmental management system were .87 and .98 . Cronbach's alpha coefficients were computing for each scale and most factors were found to have coefficients between of 0.79 to 0.98 indicating that been reliable.

\subsection{Correlation Analysis}

In this section, the Pearson correlation coefficient was implemented to understand the relation among several variables of this study. It indicated significant adverse on the potential value of the error from the first type. It was the probability number of uncertainty value which was at significance of 0.05 and 0.01 in determining the moral differences between the variables. The statistical results are shown in table 1 , which verified the hypothesis whether there is a strong correlation between leadership behaviour and environmental performance variables or otherwise.

\subsubsection{Testing Hypotheses}

$\mathbf{H}_{1}$ : explained a significant relationship between leadership behaviour of the company top management and environmental performance.

Based on the table 1, Pearson Correlation Coefficient explains the relationship between supportive leadership and total quality management was 0.066 at significance bigger than 0.01 . This means the correlation was very low and there was no significant relation between them. Further supportive leadership has very low and non-significant relationship with total quality management. $0.04 \%$ of the total variance in total quality management derived from the supportive leadership when determination coefficient was considered at $\mathrm{r}^{2}=0.004$. Pearson Correlation Coefficient value between supportive leadership and environmental management system was $0.289^{* *}$ at significance smaller than 0.01 which means the correlation is $28.9 \%$ between them. It was a significant positive correlation. This proved that supportive leadership has moderate and significant influence to environmental management system. It can said that $8.3 \%$ of the total variance in environmental management 
derived from the supportive leadership when determination coefficient was considered $r^{2}=0.083$. Meanwhile, Pearson Correlation Coefficient value between supportive leadership and total environmental performance at Akukus was $0.295^{* *}$ at significance smaller than 0.01 . It described that the correlation of both was $29.5 \%$. It indicated a significant correlation that means there is moderate and positive relationship supportive leadership and environmental performance. It determined $8.7 \%$ of the total variance of environmental performance derived from the supportive leadership when considering the determination coefficient was at $\mathrm{r}^{2}=0.087$.

Pearson Correlation Coefficient value between directive leadership and total quality management was 0.153 at significance bigger than 0.01 which means the correlation of them was very low and there is no significant correlation. $2.3 \%$ of the total variance of total quality management came from the directive leadership based on consideration of determination coefficient attained $\mathrm{r}^{2}=0.023$. Meanwhile, Pearson Correlation Coefficient value between directive leadership and environmental management system was $0.381^{* *}$ at significance smaller than 0.01 . It determined that the correlation of both was $38.1 \%$. It was a positive correlation. This value explained that directive leadership has moderate and significant relationship with environmental management system. There was $14.5 \%$ of the total variance in environmental management system initiated from the directive leadership considering the determination coefficient value was $\mathrm{r}^{2}=0.145$. Moreover, Pearson Correlation Coefficient value among directive leadership and total environmental performance at Akukus was $0.402 * *$ at significance smaller than 0.01 . There was $40.2 \%$ correlation between them. It was a significant correlation. Directive leadership has been proved that it influenced environmental performance. There was $16.2 \%$ of the total variance of environmental performance derived from the directive leadership through the observation on determination coefficient value at $\mathrm{r}^{2}=0.162$.

Table 1. The Pearson correlation coefficients of variables for leadership behaviour and environmental performance dimensions in Akakus company

\begin{tabular}{lllll}
\hline \multirow{2}{*}{ Model } & & TQM & EMS & $\begin{array}{l}\text { Total } \\
\text { Performance }\end{array}$ \\
\hline Supportive Leadership & Pearson Correlation & .066 & $.289^{* *}$ & $.295^{* *}$ \\
& Sig. (2-tailed) & .465 & .001 & .000 \\
\multirow{2}{*}{ Directive leadership } & Pearson Correlation & .153 & $.381^{* *}$ & $.402^{* *}$ \\
& Sig. (2-tailed) & .092 & .000 & .000 \\
Total Leadership Behaviour & Pearson Correlation & -- & -- & $.454^{* *}$ \\
& Sig. (2-tailed) & -- & -- & .000 \\
\hline
\end{tabular}

** Significant Correlation is at the 0.01 level (2-tailed).

* Significant Correlation is at the 0.05 level (2-tailed).

As the statistical results shown in the Table 1, Pearson Correlation Coefficient value between Total Leadership Behaviour and Environmental Performance was $0.454^{* *}$ at significant smaller than 0.01 . This means the correlation is $45.4 \%$ between them. It was a significant correlation of them. Leadership Behaviour variables have strong and significant relationship with environmental Performance variables at Akakus Oil Company. This proved the first hypothesis $\mathrm{H} 1$ mentioned above.

\subsection{Regression Analyses}

Linear regression analyses were performed to investigate the correlativity of independent variables and the dependent variable. Table 2 explained the regression result. $\mathrm{R}$ square of the multiple correlation coefficients indicates of the variance proportion of the dependent variable explained by the independent variables. The $\mathrm{R}$ that closes to 0.01 means a better linear regression model. $\mathrm{F}$ value is computed as the ratio of the mean sum of squares of the regression equation and residual. The coefficient determines the number of the increase units on the dependent variable caused by an increase of one unit in the independent variable. The detailed verifications of the second hypothesis are provided in the following. 
Table 2. Regression analyses results

\begin{tabular}{lllllll}
\hline \multirow{2}{*}{ Model } & & \multirow{2}{*}{ Adjusted R } & \multirow{2}{*}{ F } & \multirow{2}{*}{ Sig } & \multicolumn{2}{c}{ Standardized Coefficients } \\
\cline { 6 - 7 } & & & & & Beta & Sig \\
\hline Supportive Leadership & EP & 0.079 & 11.494 & 0.000 & 0.294 & 0.000 \\
(TQM,EMS) & & & & 0.402 & 0.000 \\
Directive leadership & $\begin{array}{l}\text { EP } \\
\text { (TQM, EMS) }\end{array}$ & 0.155 & 23.388 & 0.000 & 0.402 & 0.000 \\
Total Leadership Behaviour & Total E.P & 0.200 & \multirow{2}{*}{31.486} & 0.000 & 0.454 & 0.000 \\
\hline
\end{tabular}

A-Predictors: (Constant), Leadership Behaviour.

B-Dependent Variable: Environmental Performance.

\subsubsection{Testing Hypothesis}

\section{$\mathrm{H}_{2}$ : is a significant impact of leadership behaviour on the environmental performance.}

Statistical results show the relation levels between supportive leadership and environmental performance at Akakus Company which was compatible moderately. The calculation of F test attained 11.494 which were the largest indexed value of $\mathrm{F}$ at significant less than 0.01 . Coefficient $(\mathrm{R})$ consequently adjusted at value of 0.079 . It shows that the supportive leadership has explained and interpreted $7.9 \%$ in gaining changes on environmental performance. In addition, the value of the coefficient Beta (B) of the supportive leadership as an independent variable for the dependent variable of the environmental performance was positive 0.294 at significant less than 0.01. In other word, one unit change of supportive leadership increased 0.294 of environmental performance. Meanwhile, Statistical results illustrate the relation levels between directive leadership and environmental performance at Akakuls Company that was moderate. The test of $\mathrm{F}$ value determined 23.388. It was a large indexed $\mathrm{F}$ value at significant less than 0.01 . It adjusted coefficient $(\mathrm{R})$ at 0.155 . The directive leadership took $15.5 \%$ roles in attaining change towards environmental performance. The coefficient Beta (B) of the directive leadership as an independent variable for the dependent variable of the environmental performance was 0.402 at significant less than 0.01. It showed that one unit change of directive leadership increase the environmental performance about 0.402 .

Table 2 also shows regression analysis of the total leadership behaviour and environmental performance in Akakus Oil Operation Company. The test of $\mathrm{F}$ value recorded 31.486 which was a large indexed $\mathrm{F}$ value at significance less than 0.01 . The adjusted $\mathrm{R}$ was 0.200 which explained that the leadership behaviour influenced $20 \%$ on the changes of the dependent variable of environmental performance. Determination coefficient of $\mathrm{r}^{2}=$ 0.206 considered that there was $20.6 \%$ of total variance of environmental performance depend on the leadership behaviours. Moreover, the value of the coefficient Beta of leadership behaviour as an independent variable toward environmental performance was 0.454 at a minor significance than 0.001 . It can be concluded that a unit change of leadership behaviour and organizational commitment increased 0.454 of environmental management system. This fact validated the second hypotheses.

\section{Discussion}

This paper empirically investigated the correlation between leadership behavior and environmental performance within the public sector organizations in Libya. It further examined the impact of leadership behavior on overall implementation status of international standard systems as total quality management (TQM) and environmental management system (EMS). They are crucial techniques in increasing the environmental performance within the industrial organizations. Based on the investigation results, supportive and directive leadership behaviors of the top management have significant relationship and positive impact on the environmental performance within the Akakus Oil Operation Company in Libya. The statistical results have indicated a positive direct relationship and impact of two dimensions of path goal relationship model, namely supportive and directive leadership behavior with total quality and environmental management systems. This implies that the leaders who commit themselves to provide adequate and appropriate resources to implement the TQM and EMS policies, and trying endeavor gain commitment of employees to the policy by encouraging their active participation will enhance the level of environmental performance within the company. Generally, this work result supported the previous studies which conducted by Dubey et al and Daily et al. (Govindarajulu \& Daily, 2004; Dubey, Gunasekaran et al., 2015) that also concluded that the leadership have significant impact on overall implementation status of TQM and EMS and this in turn reflect on the level of environmental performance within the company. It can be said that the environmental performance level within the Akakus Company increase as leadership behavior of the top management increase. 


\section{Conclusion}

Considering all the above, present study concluded that were significant relationship between the leadership behavior and environmental performance at Akakus Oil Company, Libya. Leadership behavior affected significantly on environmental performance at Akakus Oil Company. These results indicated that techniques and philosophies of TQM and EMS are familiarity and formally implemented at high level across Akakus Oil Operation Company.

\section{References}

Beer, M. (2003). Why total quality management programs do not persist: The role of management quality and implications for leading a TQM transformation. Decision Sciences, 34(4), 623-642. http://dx.doi.org/10.1111/j.1540-5414.2003.02640

Burke, R., \& Barron, S. (2014). Project management leadership: building creative teams. John Wiley \& Sons. Wiley publisher

Chavan, M. (2005). An appraisal of environment management systems: A competitive advantage for small businesses. Management of Environmental Quality: An International Journal, 16(5), 444-463. http://dx.doi.org/10.1108/14777830510614321

Dubey, R., \& Gunasekaran, A. (2015). Exploring the relationship between leadership, operational practices, institutional pressures and environmental performance: A framework for green supply chain. International Journal of Production Economics, 160, 120-132. http://dx.doi.org/10.1016/j.ijpe.2014.10.001

Ewing, J. C., \& Bruce, J. A. (2009). Effective leadership development for undergraduates: How important is active participation in collegiate organizations.

Govindarajulu, N., \& Daily, B. F. (2004). Motivating employees for environmental improvement. Industrial Management \& Data Systems, 104(4), 364-372. http://dx.doi.org/10.1108/02635570410530775

Han, S. B., \& Chen, S. K. (2007). Effects of ISO 9000 on customer satisfaction. International Journal of Productivity and Quality Management, 2(2), 208-220. http://dx.doi.org/10.1504/IJPQM.2007.012411

Hanson, E. M. (2003). Educational Administration and Organizational Behavior. ED482615: Longman Publishing.

Haslinda, A., \& Chan, F. C. (2010). The Implementation of ISO 14001 Environmental Management System. Asian Social Science, 6(3), 100. http://dx.doi.org/10.5539/ass.v6n3p100

House, R. J. (1971). A path goal theory of leader effectiveness. Administrative Science Quarterly, 321-339.

Hoyle, D. (2009). ISO 9000 Quality Systems Handbook: Using the standards as a framework for business improvement. Routledge.

Jørgensen, T. H., \& Remmen, A. (2006). Integrated management systems-three different levels of integration. Journal of Cleaner Production, 14(8), 713-722. http://dx.doi.org/10.1016/j.jclepro.2005.04.005

Lakshman, C. (2006). A theory of leadership for quality: Lessons from TQM for leadership theory 1. Total Quality Management \& Business Excellence, 17(1), 41-60. http://dx.doi.org/10.1080/14783360500249729

Leslie, J. (2009). The leadership gap: What you need, and don't have, when it comes to leadership talent. Center for Creative Leadership.

Lunenburg, F., \& Ornstein, A. (2011). Educational administration: Concepts and practices, Cengage Learning. Watsworth Cengage Learning.

Petros Sebhatu, S., \& Enquist, B. (2007). ISO 14001 as a driving force for sustainable development and value creation. The TQM Magazine, 19(5), 468-482. http://dx.doi.org/10.1108/09544780710817883

Rollinson, D. (2008). Organisational behaviour and analysis: An integrated approach. Pearson Education.

Rui, C., \& Emerson, M. (2010). Transformational leadership and TQM implementation. Advances in Management.

Saee, J. (2005). Effecitve leadership for the global economy in the 21ST century. Journal of Business Economics and Management, 6(1), 3-11. http://dx.doi.org/10.1080/16111699.2005.9636088

Singh, A., \& Shoura, M. M. (2006). A life cycle evaluation of change in an engineering organization: A case study. International Journal of Project Management, 24(4), 337-348. http://dx.doi.org/10.1016/j.ijproman.2005.11.001 
Sinha, M., \& Karaszewski, R. (2010). Leadership in global business environment through a vision creation process. The TQM Journal, 22(4), 399-409.

Tatlah, I. A., Ali, Z. (2011). Leadership behavior and organizational commitment: An empirical study of educational professionals. International Journal of Academic Research, 3(2).

Ulubeyli, S. (2013). Drivers of environmental performance of cement plants. Industrial Management \& Data Systems, 113(8), 1222-1244. http://dx.doi.org/10.1108/IMDS-01-2013-0007

Wilkinson, G., \& Dale, B. (2001). Integrated management systems: a model based on a total quality approach. Managing Service Quality, 11(5), 318-330. http://dx.doi.org/10.1108/09604520110404040

Zutshi, A., \& Sohal, A. (2004). A study of the environmental management system (EMS) adoption process within Australasian organisations-2. Role of stakeholders. Technovation, 24(5), 371-386. http://dx.doi.org/10.1016/S0166-4972(02)00115-3

\section{Copyrights}

Copyright for this article is retained by the author(s), with first publication rights granted to the journal.

This is an open-access article distributed under the terms and conditions of the Creative Commons Attribution license (http://creativecommons.org/licenses/by/3.0/). 